\title{
Lung Inflammatory and Oxidative Alterations After Exogenous Surfactant Therapy Fortified With Budesonide in Rabbit Model of Meconium Aspiration Syndrome
}

\author{
P. MIKOLKA ${ }^{1,2}$, J. KOPINCOVÁ ${ }^{1,2}$, P. KOŠÚTOVÁ ${ }^{1,2}$, D. ČIERNY ${ }^{3}$, A. ČALKOVSKÁ ${ }^{1,2}$, \\ D. MOKRÁ ${ }^{1,2}$
}

${ }^{1}$ Biomedical Center Martin, Jessenius Faculty of Medicine in Martin, Comenius University in Bratislava, Martin, Slovakia, ${ }^{2}$ Department of Physiology, Jessenius Faculty of Medicine in Martin, Comenius University in Bratislava, Martin, Slovakia, ${ }^{3}$ Department of Clinical Biochemistry, Jessenius Faculty of Medicine in Martin, Comenius University in Bratislava, Martin, Slovakia

Received March 24, 2016

Accepted October 26, 2016

\begin{abstract}
Summary
Meconium aspiration syndrome (MAS) triggers inflammatory and oxidative pathways which can inactivate both pulmonary surfactant and therapeutically given exogenous surfactant. Glucocorticoid budesonide added to exogenous surfactant can inhibit inflammation and thereby enhance treatment efficacy. Neonatal meconium $(25 \mathrm{mg} / \mathrm{ml}, 4 \mathrm{ml} / \mathrm{kg})$ was administered intratracheally (i.t.) to rabbits. When the MAS model was prepared, animals were treated with budesonide i.t. (Pulmicort, $0.25 \mathrm{mg} / \mathrm{kg}, \mathrm{M}+\mathrm{B}$ ); with surfactant lung lavage (Curosurf ${ }^{\circledR}$, $10 \mathrm{ml} / \mathrm{kg}, 5 \mathrm{mg}$ phospholipids $/ \mathrm{ml}, \mathrm{M}+\mathrm{S}$ ) followed by undiluted Curosurf $^{\circledR}$ i.t. (100 mg phospholipids $/ \mathrm{kg}$ ); with combination of budesonide and surfactant $(\mathrm{M}+\mathrm{S}+\mathrm{B})$; or were untreated $(\mathrm{M})$; or served as controls with saline i.t. instead of meconium (C). Animals were oxygen-ventilated for additional $5 \mathrm{~h}$. Cell counts in the blood and bronchoalveolar lavage fluid (BAL), lung edema formation (wet/dry weight ratio), oxidative damage of lipids/ proteins and inflammatory expression profiles (IL-2, IL-6, IL-13, TNF- $a$ ) in the lung homogenate and plasma were determined. Combined surfactant+budesonide therapy was the most effective in reduction of neutrophil counts in BAL, oxidative damage, levels and mRNA expression of cytokines in the lung, and lung edema formation compared to untreated animals. Curosurf fortified with budesonide mitigated lung inflammation and oxidative modifications what indicate the perspectives of this treatment combination for MAS therapy.
\end{abstract}

\section{Key words}

Meconium aspiration - Exogenous surfactant • Budesonide • Inflammation • Oxidation • Lung injury

\section{Corresponding author}

D. Mokrá, Biomedical Center Martin, Jessenius Faculty of Medicine in Martin, Comenius University in Bratislava (JFM CU) and Department of Physiology JFM CU, Mala Hora 4C, SK-03601 Martin, Slovakia. E-mail: mokra@jfmed.uniba.sk

\section{Introduction}

Meconium aspiration syndrome (MAS) is a serious disease of the neonates. The pathophysiology of MAS involves airway obstruction by meconium, dysfunction of pulmonary surfactant, inflammation, ventilation-perfusion mismatch, pulmonary vasoconstriction, lung edema, and airway hyperreactivity.

Aspirated meconium triggers the inflammation via TLR4/MD-2 CD14 signaling complex leading to increase in transcription factor nuclear factor $\mathrm{KB}(\mathrm{NF}-\mathrm{KB})$ (Salvesen et al. 2010). NF-KB translocation initiates simultaneously both pro-oxidative and inflammatory cascades. Meconium itself and meconium-stained amniotic fluid are rich sources of cytokines IL-1 $\beta$, IL-6, IL- 8 and TNF- $\alpha$ (de Beaufort et al. 2003). Damage to the alveolar-capillary membrane and action of chemotactic IL-8 present in meconium provoke intrapulmonary sequestration of neutrophils. Excessive activation of cells leads to oxidative damage of the tissue by release of cytotoxic and immune cell-activating agents such as proteinases, cationic polypeptides, cytokines, and reactive oxygen and nitrogen species (RONS) through their 
oxidant-generating systems. Vice versa, oxidative stress can increase production of pro-inflammatory cytokines (Grommes and Soehnlein 2011).

The complex action of oxidative processes and inflammation, components of aspirated meconium and plasma proteins leaking through the alveolar-capillary membrane finally deteriorates the alveolar type II cells. This results in decreased production and function of surfactant, and alveolar collapse. Dysfunction of endogenous surfactant can be mitigated by administration of exogenous surfactant. However, the above mentioned processes may also affect exogenous surfactant delivered as a therapy (Nkadi et al. 2009). From this reason, suppression of oxidation and inflammation appears to be advantageous, as it may diminish inactivation of given surfactant and thereby enhance efficacy of the surfactant therapy.

For this purpose, synthetic glucocorticoid budesonide was chosen for inhibition of inflammation and inflammation-induced oxidation modification. Glucocorticoids (GCs) suppress NF-KB and consequently the expression of NF-KB-dependent pro-inflammatory gene. Thus, they inhibit the transcription of cytokines relevant for acute lung injury, e.g. IL-1, IL-3, IL-4, IL-5, IL-6, IL-8, TNF- $\alpha$, and granulocyte-macrophage colonystimulating factor. GCs also act on the antagonist of IL-1 receptor and on anti-inflammatory cytokines IL-4, IL-10, and IL-13 with synergy to control the host-defense response. GCs stimulate apoptosis of T-cells, eosinophils, and monocytes, inhibit neutrophil activation, and maintain endothelial integrity and vascular permeability (Fernandes et al. 2005, Newton et al. 2010). Previous experimental (Kirimi et al. 2003, Mokra et al. 2007) and clinical studies (da Costa et al. 2001, Basu et al. 2007) showed that systemically given GCs improve the lung function in MAS, however, can be accompanied with adverse effects (Mokra et al. 2008).

Therefore, we have assumed that addition of glucocorticoid directly into exogenous surfactant for intratracheal (i.t.) delivery can affect local injury and reduce the secondary surfactant inactivation. This study determined whether budesonide can mitigate inflammation and oxidation in the meconium-injured lung and whether its administration coupled with surfactant may enhance the efficacy in comparison with monotherapies (surfactant or budesonide). For this purpose, young rabbits were used for creation of MAS model as body weight and size of the airways are comparable to neonates what is particularly important in studies with application of different ventilation techniques or lung lavage with diluted surfactant (Ohama and Ogawa 1999, Lam et al. 2000, Calkovska et al. 2008).

\section{Methods}

\section{Animals}

For experiments, eight-week-old New Zealand white rabbits (supplied by Department of Toxicology and Laboratory Animal Breeding Station, Dobra Voda, Slovakia) of both genders with a body weight of $1.9 \pm 0.2 \mathrm{~kg}, \mathrm{n}=33$ in total were used. Animals were divided into 5 groups according to the treatment: meconium-instilled untreated group $(\mathrm{M}, \mathrm{n}=7)$, meconium-instilled and surfactant-treated group $(\mathrm{M}+\mathrm{S}$, $\mathrm{n}=7$ ), meconium-instilled and budesonide-treated group $(\mathrm{M}+\mathrm{B}, \quad \mathrm{n}=5), \quad$ meconium-instilled and surfactant + budesonide treated group $(\mathrm{M}+\mathrm{S}+\mathrm{B}, \mathrm{n}=7)$, and controls with i.t. saline instilled instead of meconium $(C, n=7)$.

\section{Meconium, exogenous surfactant, budesonide}

First-pass meconium was collected from diapers of 25 healthy term neonates born in University Hospital in Martin, Slovakia. Meconium was pooled, lyophilized and stored at $-20^{\circ} \mathrm{C}$. Before i.t. instillation, meconium was suspended in $0.9 \% \mathrm{NaCl}$ at a concentration of $25 \mathrm{mg} / \mathrm{ml}$.

Modified porcine surfactant (Curosurf $\AA$, Chiesi Farmaceutici, Italy; $80 \mathrm{mg}$ phospholipids (PL)/ml) was used for surfactant therapy. For therapeutic lung lavage (i.e. for washout of meconium), Curosurf was diluted in saline to a PL concentration of $5 \mathrm{mg} / \mathrm{ml}$. After the lung lavage, a supplementation dose of Curosurf in undiluted form was administered i.t. at a dose of $100 \mathrm{mg} / \mathrm{kg}$ to recover loss of endogenous surfactant by the lavage procedure.

Budesonide (Pulmicort susp inh, AstraZeneca, $0.5 \mathrm{mg} / \mathrm{ml}$ ) at a dose of $0.25 \mathrm{mg} / \mathrm{kg}$ was used for i.t. administration as a monotherapy $(\mathrm{M}+\mathrm{B})$ or added to a supplementation dose of Curosurf $(\mathrm{M}+\mathrm{S}+\mathrm{B})$.

\section{General protocol of experiments}

Experiments were carried out in accordance with the European Guidelines on Laboratory Animal Care, and were authorized by the local Ethics Committee of JFM CU in Martin (EK 609/2010) and National Veterinary Board of Slovak Republic (Ro-1254/10-221).

Animals were anesthetized with intramuscular 
ketamine (20 mg/kg; Narketan, Vétoquinol Ltd., UK) and xylazine (5 mg/kg; Xylariem, Riemser, Germany), followed by i.v. infusion of ketamine $(20 \mathrm{mg} / \mathrm{kg} / \mathrm{h})$. A tracheostomy was performed and an endotracheal cannula was inserted. Catheters were inserted into the femoral artery for blood sampling and monitoring blood pressure and into the femoral vein for continuous ketamine infusion. After abortion of spontaneous breathing by pipecuronium bromide $(0.3 \mathrm{mg} / \mathrm{kg} / 30 \mathrm{~min}$ i.v.; Arduan, Gedeon Richter, Hungary) animals were ventilated by ventilator Beat-2 (Chirana, Slovakia) with following settings: frequency (f) of $30 / \mathrm{min}$, fraction of inspired oxygen $\left(\mathrm{FiO}_{2}\right)$ 0.21, inspiration time (Ti) $50 \%$, peak inspiratory pressure (PIP) adjusted to keep a tidal volume $\left(\mathrm{V}_{\mathrm{T}}\right)$ of $7-9 \mathrm{ml} / \mathrm{kg}$, and no positive end-expiratory pressure (PEEP). After $15 \mathrm{~min}$ of stabilization, meconium (M groups) or saline (C group) at a dose of $4 \mathrm{ml} / \mathrm{kg}$ were instilled i.t. in semi-upright right and left lateral positions of the animal. Subsequently, $\mathrm{FiO}_{2}$ was increased to 1.0, PEEP to $3 \mathrm{~cm} \mathrm{H}_{2} \mathrm{O}$ to avoid atelectasis of alveoli and PIP to supply $\mathrm{V}_{\mathrm{T}}$ of $7-9 \mathrm{ml} / \mathrm{kg}$. Within $30 \mathrm{~min}$, meconium instillation caused respiratory insufficiency defined as $>30 \%$ decrease in dynamic lung-thorax compliance $\left(\mathrm{C}_{\text {dyn }}\right)$ and $\mathrm{PaO}_{2}<10 \mathrm{kPa}$ at $\mathrm{FiO}_{2}$ 1.0. When the criteria for MAS model set according to the literature (Lam et al. 2000, Calkovska et al. 2008, Wang et al. 2010) were fulfilled, animals were treated (see below). After the treatment delivery, animals were ventilated for additional $5 \mathrm{~h}\left(\mathrm{FiO}_{2} 1.0, \mathrm{f}=30 / \mathrm{min}, \mathrm{V}_{\mathrm{T}} 7-9 \mathrm{ml} / \mathrm{kg}\right.$, PEEP $\left.3 \mathrm{~cm} \mathrm{H} \mathrm{H}_{2} \mathrm{O}\right)$, and then overdosed by anesthetics. The left lung was lavaged with saline $(3 \times 10 \mathrm{ml} / \mathrm{kg})$ and diagnostic BAL fluid was centrifuged (1500 rpm for $15 \mathrm{~min}$ ) to obtain cell-rich sediment. The right lung was assessed for lung edema formation, or stored at $-70^{\circ} \mathrm{C}$ natively or in RNA stabilization solution (RNAlater, QIAGEN Group) until biochemical analyses were performed.

\section{Administration of the treatment}

Surfactant therapy ( $\mathrm{M}+\mathrm{S}$ group) consisted of the lung lavage with diluted surfactant (Curosurf, $10 \mathrm{ml} / \mathrm{kg}$, $5 \mathrm{mg} \mathrm{PL} / \mathrm{ml}$ ) given twice in the semi-upright right and left lateral animal positions, each followed by a tracheal suction using suction device. This maneuver served for partial washout of instilled meconium. Subsequently, a dose of undiluted Curosurf (100 mg PL/kg, $1.25 \mathrm{ml} / \mathrm{kg}$ ) was administered via jet of ventilator using asymmetric high-frequency jet ventilation (or inpulsion regime of HFJV) (f. 300/min, Ti $20 \%$, PIP/PEEP $15 / 3 \mathrm{~cm} \mathrm{H}_{2} \mathrm{O}$ ) to supplement the loss of endogenous surfactant caused by lavage and/or inactivation by meconium.

Budesonide $\quad(0.25 \mathrm{mg} / \mathrm{kg}, \quad 0.5 \mathrm{ml} / \mathrm{kg}) \quad$ was administered intratracheally by asymmetric HFJV as a monotherapy $(\mathrm{M}+\mathrm{B}$ group) or added into the dose of undiluted Curosurf as a combined therapy ( $\mathrm{M}+\mathrm{S}+\mathrm{B}$ group) by a similar manner as described above.

\section{Cell counts in the blood and BAL fluid}

Differential white blood cell counts in the arterial blood and cell counts in the sediment of diagnostic BAL fluid were estimated microscopically after staining by May-Grünwald/Giemsa-Romanowski. The counts of cells were expressed in percents (\%).

Biochemical analysis of oxidative modification and cytokine concentration in the lung

Concentrations of cytokines and oxidative modification products were determined in $10 \%$ (weight/volume) lung homogenate prepared using $0.1 \mathrm{M}$ phosphate buffer (PBS, pH 7.4) by Polytron homogenizer PT 1200 E (Kinematica AG, Switzerland). Oxidative damage to proteins was determined using OxiSelect ${ }^{\mathrm{TM}}$ Nitrotyrosine ELISA Kit (Cell Biolabs, Inc., USA) and expressed as concentration of 3-nitrotyrosine in nanomoles (nM 3NT). Oxidative damage to lipids expressed as concentration of thiobarbituric acid reacting substances (TBARS) was determined by OxiSelect ${ }^{\mathrm{TM}}$ TBARS Assay Kit (Cell Biolabs Inc., USA), and was shown as concentration of malondialdehyde in micromoles ( $\mu \mathrm{M}$ MDA). To evaluate the changes in oxidative status in plasma, concentrations of $3 \mathrm{NT}$ and MDA were detected in initial (P1) and final (PF) plasma and expressed as a ratio PF/P1. Concentrations of IL-2, IL-6, IL-13 and TNF- $\alpha$ were quantified in duplicate using rabbit-specific ELISA kits (USCN Life Science Inc., China) according to the manufacturer's instructions and expressed in $\mathrm{pg} / \mathrm{ml}$.

Cytokines expression profile using real-time quantitative PCR

Stabilized lung tissue was homogenized and total RNA was isolated using RNeasy $^{\circledR}$ Mini Kit (QIAGEN Group) followed by cDNA producing using QuantiTect $^{\circledR}$ Reverse Transcription Kit (QIAGEN Group). Rabbit-specific primer sequences for hypoxanthine phosphoribosyl transferase (HPRT) as a reference gene for normalization, forward $(\mathrm{F})$ : 5'-TGATAGATCCATTCCTATGACTGTAGA-3' and reverse (R): 5'-GGGTCCTTTTCACCAGCAG-3'; 
for IL-2, F: 5'-TGAAACATCTTCAGTGTCTAGAAG-3' and R: 5'-CATTGTAGAATTTCTGAACAGAT-3'; for IL-6, F: 5'-TAGTCCTTCCTACCCAATTTCC-3' and R: 5'-TTGGTCCTTAGCCACTCCTTC-3'; for IL-13, F: 5'-GCAAATAATGAGCTTTCGAAGTTTCAGTGG-3' R: 5'-CTTCCGTGAGGACTGAATGAGACGGTC-3'; for TNF- $\alpha$, F: 5'-GTCTTCCTCTCTCACGCACC-3' and R: 5'-TGGGCTAGAGGCTTGTCACT-3'. Quantitative real-time PCR (RT-qPCR) was performed in triplicates using the iCycler iQ5 ${ }^{\circledR}$ (Bio-Rad Laboratories Inc.) and QuantiTect SYBR ${ }^{\circledR}$ Green PCR Kit (QIAGEN Group). The amplification cycling conditions were as follows: an initial denaturation step at $95^{\circ} \mathrm{C}$ for $2 \mathrm{~min}$, followed by 45 cycles of denaturation at $95{ }^{\circ} \mathrm{C}$ for $15 \mathrm{~s}$, annealing at $60{ }^{\circ} \mathrm{C}$ for $1 \mathrm{~min}$, and extension at $72{ }^{\circ} \mathrm{C}$ for $30 \mathrm{~s}$. The crossing point or the cycle number at which the fluorescence of the sample exceeded that of the background, was determined by the Bio-Rad iQ5 Standard Edition Optical System Software 2.0 using the second derivative method.

\section{Lung edema formation}

Strips of the right lung were weighed before and after drying in an oven at $60^{\circ} \mathrm{C}$ for $48 \mathrm{~h}$. Wet to dry (W/D) lung weight ratio expressed an extent of lung edema formation.

\section{Statistical analysis}

Data are presented as means \pm SEM. Statistical analysis was performed using statistic software Graph Pad Prism 5 (USA). The differences among the groups were analyzed by Kruskal-Wallis non-parametric test with a Dunn's multiple all pairs comparison test. A $p$ value $<0.05$ was considered to be statistically significant.

\section{Results}

\section{Cell counts in the arterial blood and BAL fluid}

In the blood, percentage of neutrophils decreased after meconium instillation compared to controls (M vs. $\mathrm{C} p<0.01)$. The circulating neutrophils elevated after all therapies, but significant difference was observed only in both budesonide-treated groups compared to untreated group ( $\mathrm{M}+\mathrm{B}$ vs. $\mathrm{M} p<0.05, \mathrm{M}+\mathrm{S}+\mathrm{B}$ vs. $\mathrm{M} p<0.01)$. Percentage of monocytes/macrophages decreased slightly in all meconium-instilled groups compared to controls (Fig. 1).

In the BAL fluid, percentage of neutrophils increased after meconium instillation compared to controls (M vs. C $p<0.001$ ). The therapies decreased neutrophil leak into the lung whereas this reduction was significant only for combined therapy compared to untreated group $(\mathrm{M}+\mathrm{S}+\mathrm{B}$ vs. $\mathrm{M} \quad p<0.05)$ and to budesonide-treated group $(\mathrm{M}+\mathrm{S}+\mathrm{B}$ vs. $\mathrm{M}+\mathrm{B} p<0.05)$. Contrary, monocytes/macrophages decreased after meconium instillation compared to controls (M vs. C $p<0.001)$. Only combined therapy elevated their percentage significantly compared to untreated group and budesonide-treated group $(\mathrm{M}+\mathrm{S}+\mathrm{B}$ vs. $\mathrm{M}$ and $\mathrm{M}+\mathrm{S}+\mathrm{B}$ vs. $\mathrm{M}+\mathrm{B}$, for both $p<0.05$ ) (Fig. 1).

\section{Oxidative modifications in the lung tissue and plasma}

Oxidative damage to proteins in the lung and plasma expressed as 3-nitrotyrosine (3NT) increased in the meconium-instilled untreated group compared to controls (in lung $\mathrm{M}$ vs. C $p<0.05$, in plasma $p<0.01$ ). Given therapies lowered the protein oxidation compared to the untreated animals, whereas this effect was significant only for surfactant+budesonide combination (in lung $\mathrm{M}+\mathrm{S}+\mathrm{B}$ vs. $\mathrm{M} p<0.001$, in plasma $p<0.05$; Fig. 2).

Oxidative damage to lipids expressed by formation of malondialdehyde was higher in meconiuminstilled untreated group compared to controls (M vs. C $p<0.01$ in lung, $p<0.05$ in plasma). Lung concentration of MDA in all treated groups decreased compared to untreated group, but significantly only for combined therapy $(\mathrm{M}+\mathrm{S}+\mathrm{B}$ vs. $\mathrm{M} p<0.01)$. In plasma of both surfactant-treated groups, reduced lipid damage compared to untreated group was found, whereas combined therapy was superior to surfactant alone $(\mathrm{M}+\mathrm{S}+\mathrm{B}$ vs. $\mathrm{M} p<0.001, \mathrm{M}+\mathrm{S}$ vs. $\mathrm{M} p<0.05)$ and budesonide alone $(\mathrm{M}+\mathrm{S}+\mathrm{B}$ vs. $\mathrm{M}+\mathrm{B} p<0.01$; Fig. 2$)$.

\section{Cytokine production in the lung}

Concentrations of IL-2 $(p<0.001)$, IL-6 and TNF- $\alpha$ (both $p<0.05$ ) in the lung homogenate of meconium-instilled untreated group elevated compared to controls, except IL-13 where no difference was observed ( $\mathrm{M}$ vs. C $p>0.05$ ). However, all therapies reduced the cytokine production, only the combined therapy showed significant effect compared to untreated group $(\mathrm{M}+\mathrm{S}+\mathrm{B}$ vs. $\mathrm{M}$, for IL-6 $p<0.01$, for IL-13 $p<0.001$, for both TNF- $\alpha$ and IL-2 $p<0.05)$, to surfactant monotherapy (TNF- $\alpha$ : $\mathrm{M}+\mathrm{S}+\mathrm{B}$ vs. $\mathrm{M}+\mathrm{S} p<0.05$ ) and to budesonide monotherapy (IL-6: $\mathrm{M}+\mathrm{S}+\mathrm{B}$ vs. $\mathrm{M}+\mathrm{B} p<0.05$; Fig. 3 ). 
BAL

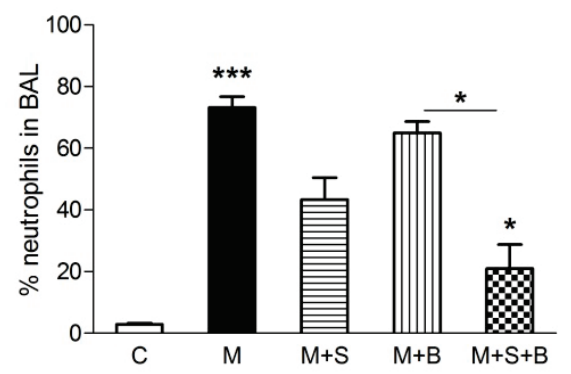

Neutrophils

Blood

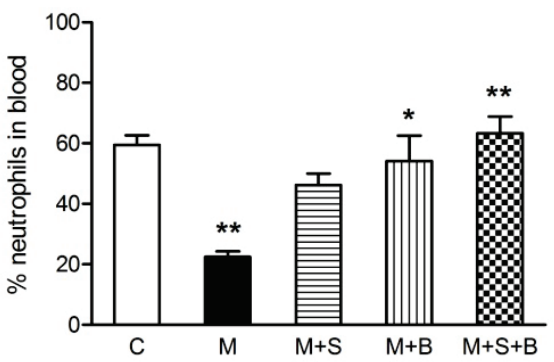

Monocytes/Macrophages

BAL

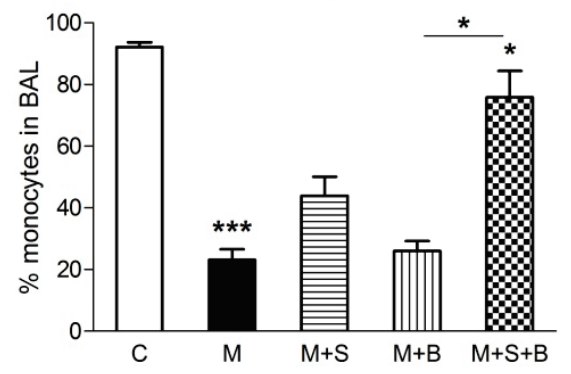

Blood

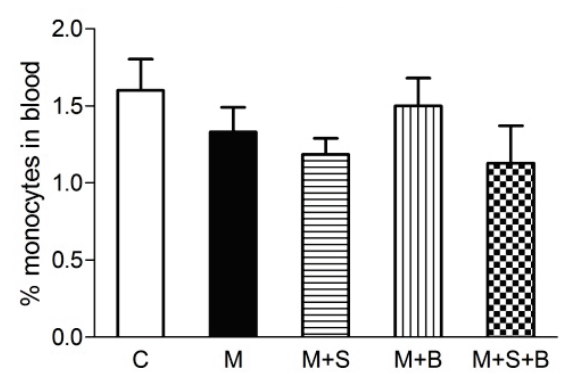

Fig. 1. Neutrophils and monocytes/macrophages in the blood and BAL fluid (expressed in \%) at the end of experiment in saline-instilled controls $(C)$, meconium-instilled untreated group $(M)$, meconium-instilled and surfactant-treated $(M+S)$ group, meconium-instilled and budesonide-treated $(\mathrm{M}+\mathrm{B})$ group, and meconium-instilled and surfactant+budesonide treated $(\mathrm{M}+\mathrm{S}+\mathrm{B})$ group. Statistical comparisons: $M$ vs. $C ; M+S$ and $M+B$ and $M+S+B$ vs. $M: * p<0.05, * * p<0.01, * * * p<0.001$.

\section{Protein oxidation}
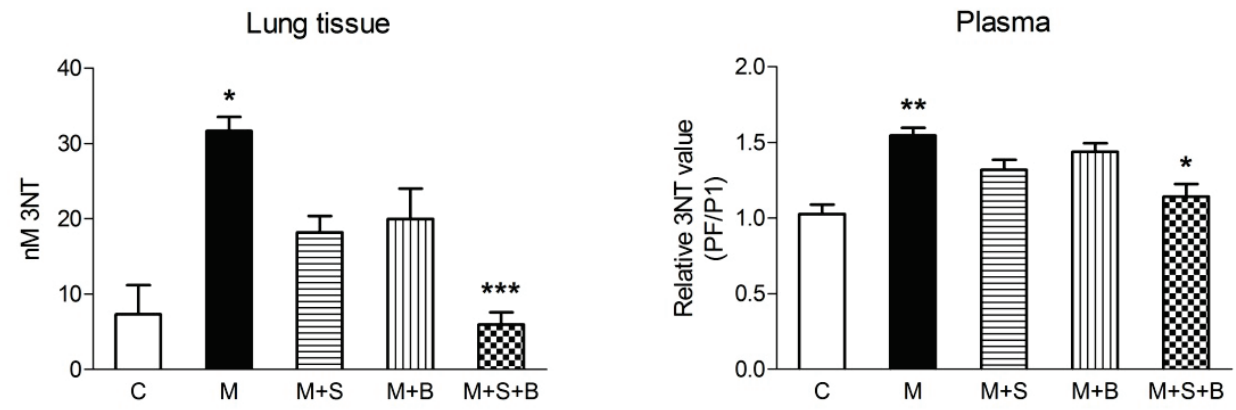

\section{Lipid oxidation}
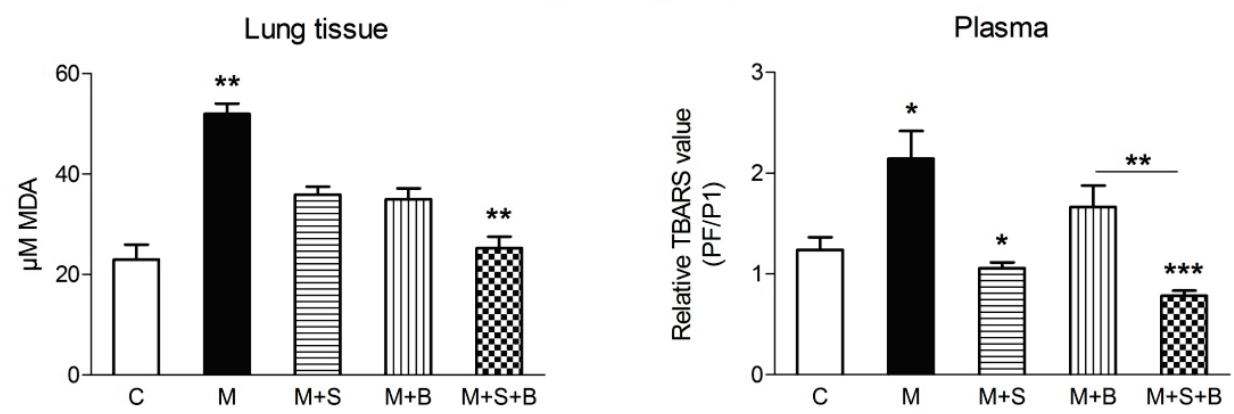

Fig. 2. Oxidative modifications in lung tissue and plasma of saline-instilled controls (C), meconium-instilled untreated group ( $M$ ), meconium-instilled and surfactant-treated $(M+S)$ group, meconium-instilled and budesonide-treated (M+B) group, and meconiuminstilled and surfactant+budesonide treated $(M+S+B)$ group. Marker of protein oxidation 3-nitrotyrosine [expressed in nanomole concentration (nM 3NT)] and marker of lipid oxidation thiobarbituric acid-reactive substances [TBARS expressed in micromole concentration of malondialdehyde ( $\mu \mathrm{mol} \mathrm{MDA})$ ]. Statistical comparisons: $\mathrm{M}$ vs. $\mathrm{C} ; \mathrm{M}+\mathrm{S}$ and $\mathrm{M}+\mathrm{B}$ and $\mathrm{M}+\mathrm{S}+\mathrm{B}$ vs. $\mathrm{M}$ : $* p<0.05$, ** $p<0.01$, *** $p<0.001$. 
TNF $\alpha$

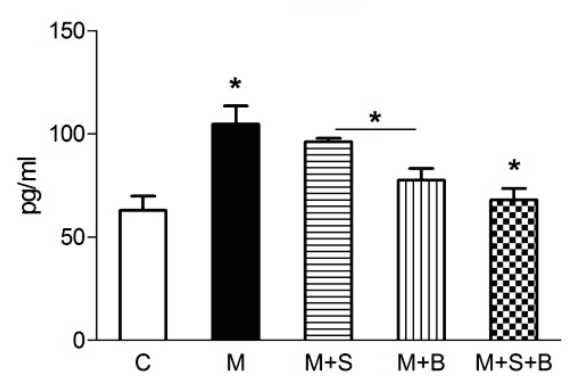

IL - 6

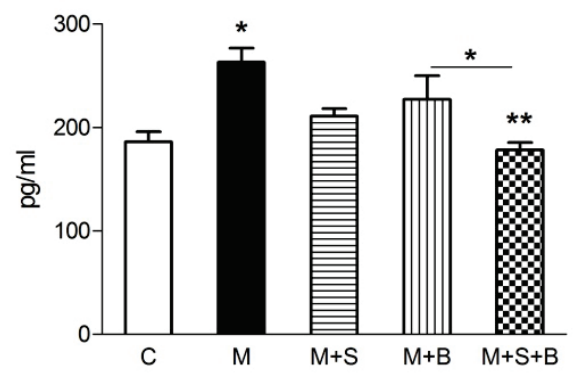

IL - 2

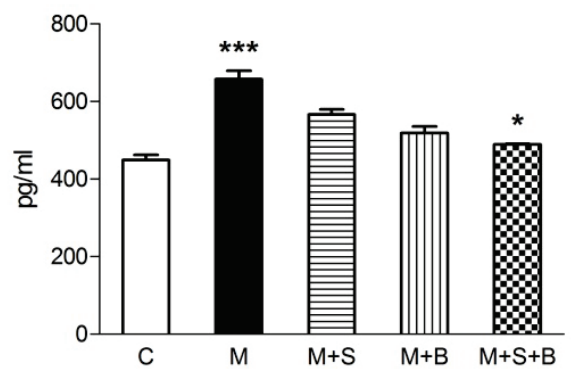

IL -13

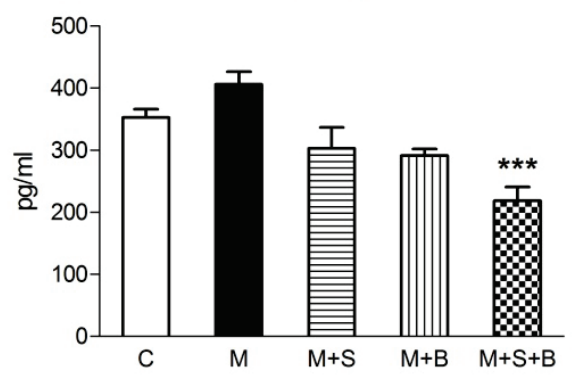

Fig. 3. Concentrations of IL-2, IL-6, IL-13 and TNF-a in the lung tissue measured using ELISA method (expressed in $\mathrm{pg} / \mathrm{ml}$ ) in the saline-instilled controls $(C)$, meconium-instilled untreated group $(M)$, meconium-instilled and surfactant-treated $(M+S)$ group, meconium-instilled and budesonide-treated $(M+B)$ group, and meconium-instilled and surfactant+budesonide treated ( $M+S+B)$ group. Statistical comparisons: $M$ vs. $C ; M+S$ and $M+B$ and $M+S+B$ vs. $M: * p<0.05, * * p<0.01, * * * p<0.001$.

TNF $\alpha$

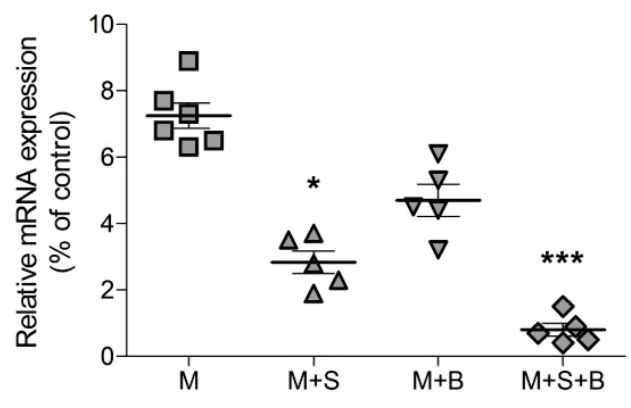

IL - 6

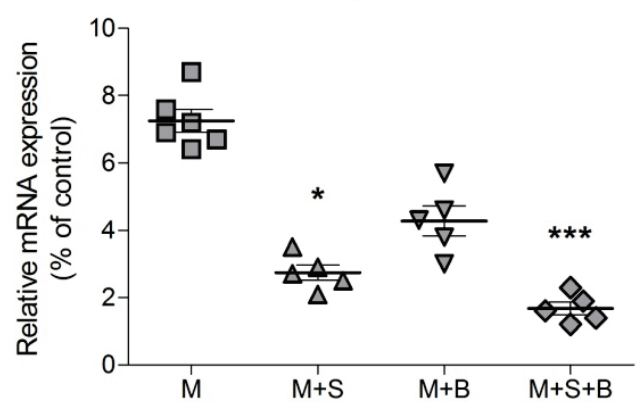

IL - 2

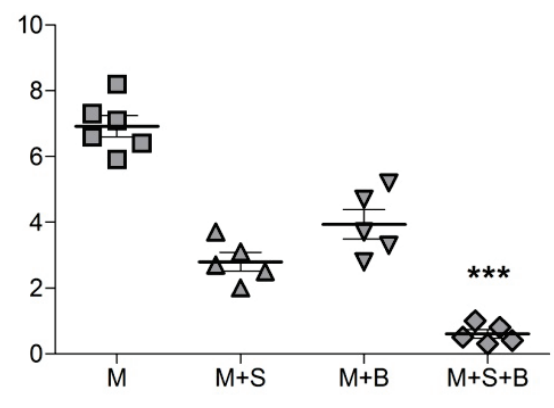

IL - 13

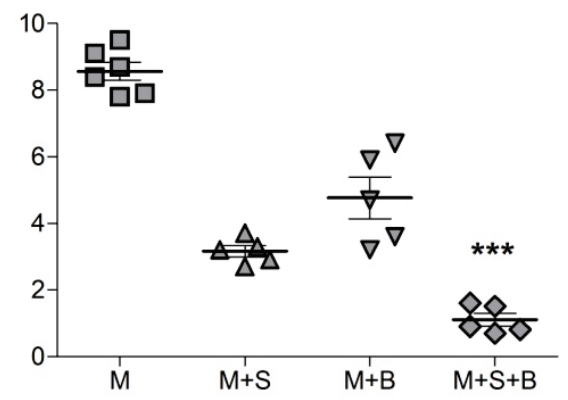

Fig. 4. Expression profile of cytokines IL-2, IL-6, IL-13 and TNF-a in the lung tissue using RT-PCR method in the meconium-instilled untreated group $(M)$, meconium-instilled and surfactant-treated $(M+S)$ group, meconium-instilled and budesonide-treated $(M+B)$ group, meconium-instilled and surfactant+budesonide treated $(\mathrm{M}+\mathrm{S}+\mathrm{B})$ group. The each geometric symbol represents the relative expression value of control $(C=1.0)(\% C)$ and is normalized to HPRT level for each animal separately. The horizontal line represents the average value of each group. Statistical comparisons: $\mathrm{M}+\mathrm{S}$ and $\mathrm{M}+\mathrm{B}$ and $\mathrm{M}+\mathrm{S}+\mathrm{B}$ vs. $\mathrm{M}$ : $* p<0.05, * * p<0.01, * * * p<0.001$. 
mRNA expression profile of cytokines in the lung tissue

To evaluate the relative changes of mRNA expression of cytokines in the lung tissue, saline-instilled animals (controls, C) were used as a calibrator group with an absolute genetic expression value of 1 , with values over or below representing higher or lower gene expression. Thus, the cytokine expression was expressed in percents derived from controls and data are shown in Figure 4. Expression of all cytokines was obviously elevated in meconium-instilled untreated group compared to controls. Compared to untreated group, gene expression of all cytokines decreased significantly after combined therapy $(\mathrm{M}+\mathrm{S}+\mathrm{B}$ vs. $\mathrm{M} p<0.001)$ and partially also after surfactant monotherapy (IL-6 and TNF- $\alpha$ : $\mathrm{M}+\mathrm{S}$ vs. M $p<0.05$ ). No differences between the therapies were observed (Fig. 4).

\section{Lung edema formation}

Formation of lung edema expressed as W/D ratio was higher in meconium-instilled untreated group compared to controls ( $\mathrm{M}$ vs. $\mathrm{C} p<0.01$ ). The W/D ratio significantly decreased in combined therapy compared to untreated group $(\mathrm{M}+\mathrm{S}+\mathrm{B}$ vs. $\mathrm{M} p<0.01)$ and to budesonide-treated group $(\mathrm{M}+\mathrm{S}+\mathrm{B}$ vs. $\mathrm{M}+\mathrm{B} p<0.05$; Fig. 5) what indicates antiedematous potential of the combined treatment.

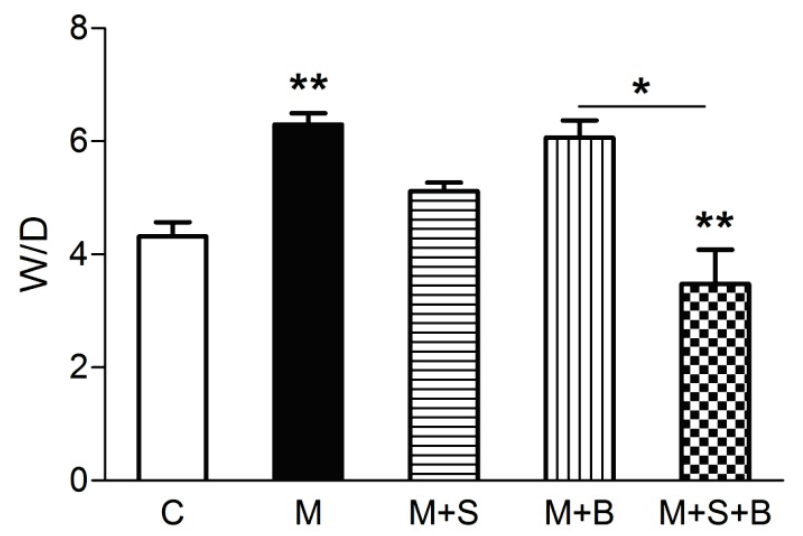

Fig. 5. Lung edema formation expressed as wet-dry (W/D) lung weight ratio in the saline-instilled controls (C), meconium-instilled untreated group (M), meconium-instilled and surfactant-treated $(M+S)$ group, meconium-instilled and budesonide-treated $(M+B)$ group, and meconium-instilled and surfactant+budesonide treated $(M+S+B)$ group. Statistical comparisons: $M$ vs. $C ; M+S$ and $\mathrm{M}+\mathrm{B}$ and $\mathrm{M}+\mathrm{S}+\mathrm{B}$ vs. $\mathrm{M}:{ }^{*} p<0.05, * * p<0.01, * * * p<0.001$.

\section{Discussion}

Mechanisms of pathophysiology of MAS interact to a large extent. Properly chosen therapy can suppress the individual factors and thereby to improve the status of neonates. This experimental study showed that exogenous surfactant enriched with budesonide reduces the meconium-induced neutrophil migration into the lung, production of pro-inflammatory cytokines and oxidation modifications of proteins and lipids, and formation of lung edema.

Substitution of inactivated pulmonary surfactant by the exogenous one has become a part of the therapeutic protocol in severe MAS (Dargaville et al. 2003). In this study, lung lavage with diluted surfactant was performed twice to remove a part of instilled meconium. The lavage was followed by administration of undiluted surfactant to substitute the components of surfactant lost by inactivation and/or lavage procedure. Nevertheless, due to oxidative modifications and on-going inflammation the surfactant therapy can be insufficient and repetitive doses of surfactant are required (Nkadi et al. 2009). To avoid this situation, surfactant can be delivered together with suitable anti-inflammatory drug. We have recently shown that anti-inflammatory drugs (budesonide, $\mathrm{N}$-acetylcysteine) added to surfactant improve respiratory functions and mitigate inflammation and oxidation in animals with MAS (Mikolka et al. 2013, Mikolka et al. 2016). In this article, effects of surfactant+budesonide combination on oxidative modifications and inflammatory profile on protein and expression levels in the lung tissue are reported.

Aspiration of meconium is an initial factor for MAS. Particles of meconium obstruct the airways and contribute to hypoxemia, hypercapnia, and respiratory acidosis leading to pulmonary vasoconstriction and increase in right-to-left pulmonary shunts (Kattan et al. 2013). Furthermore, meconium is a source of deleterious substances such as bile acids, bile salts, bilirubin, cholesterol, tri-, di- and monoglycerides, free fatty acids, heme, enzymes including pancreatic phospholipase $\mathrm{A}_{2}$, and cytokines (de Beaufort et al. 2003) which inactivate pulmonary surfactant, trigger oxidation and inflammation, and damage the endothelial and epithelial cells. In experimental animals with meconium instillation, similar symptoms expressing a significant deterioration of the lung function can be observed. Meconium in a concentration of $25 \mathrm{mg} / \mathrm{ml}$ and a dose of $4 \mathrm{ml} / \mathrm{kg}$ b.w. decreases lung compliance of about $40-50 \%$ compared to the initial value and worsens gas exchange within $30 \mathrm{~min}$ after meconium instillation (Mikolka et al. 2013).

As mentioned above, MAS is associated with a local inflammation involving several types of immune 
cells. As the earliest cells recruited to the site of injury or inflammation neutrophils have been identified. Homing of leukocytes is mediated through adhesion molecules, e.g. $\beta_{2}$-integrins $\mathrm{CD} 1 \mathrm{~b} / \mathrm{CD} 18$ which also indicate polymorphonuclear activation. Enhanced expression of $\mathrm{CD} 11 \mathrm{~b}$ in neutrophils was detected in in vitro exposure to meconium and increased expression of CD11b and CD18 was identified in granulocytes sequestered in the lung (Castellheim et al. 2005). Other potent chemoattractant for neutrophils is IL-8 which is present in meconium (de Beaufort et al. 2003). In accordance with the mentioned facts, we have found an increased percentage of neutrophils in the diagnostic BAL fluid of meconiuminstilled untreated animals compared to controls which was associated with their decreased percentage in the blood.

Surfactant lung lavage removes a portion of instilled meconium (Dargaville et al. 2003), and thereby reduces the pro-inflammatory and chemotactic stimuli in the lung and prevent a leak of cells into the lung linked with their increase in the peripheral blood as we could observe it in the surfactant-treated groups compared to untreated animals. Neutrophil sequestration into the lung is further inhibited by budesonide via inhibition of expression of vascular cell adhesion molecule-1 (VCAM-1) (Wilson et al. 2001) and inhibition of neutrophil chemotaxis and production of proinflammatory proteins (e.g. IL-6, IL-8 and CXCL1) (Strandberg et al. 2010). In this study, actions of both budesonide and surfactant were additive as we could observe it on significant decrease of neutrophils in the BAL fluid only in combined therapy in contrast to monotherapies using multiple all pairs comparison test. Similar results were found in combination of surfactant and N-acetylcysteine (Mikolka et al. 2016).

Although neutrophil activation is vital for a host defence, overzealous activation leads to a tissue damage. Neutrophils release various agents such as proteinases, cationic polypeptides, cytokines, and RONS through their oxidant-generating systems comprising the phagocyte NADPH oxidase and nitric oxide synthase (NOS). Neutrophil-induced lung damage and increased RONS in the alveolar spaces were demonstrated in patients with ALI/ARDS (Lang et al. 2002). In our experiments, meconium aspiration provoked oxidative changes in the lung and plasma, whereas protein nitrosylation was verified as increased 3-nitrotyrosine and lipid peroxidation as elevated TBARS concentrations. In agreement to our results, stimulated neutrophil oxidative burst as a meconium-mediated effect was previously published in in vitro studies (Soukka et al. 2002, Craig et al. 2005).

Considering the mentioned facts, administration of GCs reducing neutrophil activation and sequestration seems to be reasonable. In this study, exogenous surfactant combined with budesonide prevented oxidative damage in the lung and plasma when significantly reduced the levels of $3 \mathrm{NT}$ and TBARS compared to untreated group. Pro-inflammatory cytokines and oxidative stress could interact through redox sensitive transcription factor NF-KB. Production of $3 \mathrm{NT}$ results from induction of NOS mediated through NF-KB, which is inhibited by GCs (Wilson et al. 2001, Fernandes et al. 2005).

The inflammatory response associated with MAS could be detected early after meconium aspiration. Meconium activates TLR4 receptor complex CD14/TLR4/MD-2, which is also associated with lipopolysaccharide (LPS)-induced response (Salvesen et al. 2010). In addition, meconium itself is a source of IL-1, IL-6, IL-8, and TNF- $\alpha$ which may induce inflammation directly or through the stimulation of neutrophil oxidative burst. Similarly, NF-kB could be induced by IL-1 and TNF- $\alpha$ contained in meconium (Soukka et al. 2002, de Beaufort et al. 2003). In our study, cytokine mRNA expression and concentrations of IL-2, IL-6, IL-13, and TNF- $\alpha$ in the lung significantly increased in the meconium-instilled group compared to controls, what corresponds with our recent work and findings of other authors (Bhatia and Moochhala 2004, Mikolka et al. 2016). The given treatments downregulated the cytokine expression what correlated with lower concentrations of cytokines in the lung. However, superior effect was observed after combined treatment what is likely related to partial removal of meconium and local anti-inflammatory action of budesonide, finally leading to reduced activation of NF-KB (Wilson et al. 2001, Fernandes et al. 2005). Significant differences were observed between $\mathrm{M}$ and $\mathrm{M}+\mathrm{S}$ group using nonparametric Mann-Whitney U test, but significance did not survive the multiple comparison.

The complex action of meconium and proinflammatory substances damage the endothelial and epithelial cells and thereby increase the permeability across the alveolar-capillary membrane, resulting in a pulmonary edema (Dargaville et al. 2003). For instance, RONS induced in inflammation and phospholipase $\mathrm{A}_{2}$ present in meconium can disrupt intercellular connections 
in endothelium and/or induce apoptosis and necrosis of alveolar cells (Kääpä and Soukka 2008). In our study, extent of lung edema formation was expressed from the wet-dry (W/D) lung weight ratio. Significantly higher W/D value in the meconium-instilled group indicated increased accumulation of liquid in the tissue. Despite there was a trend to decrease W/D ratio also in surfactanttreated group $(\mathrm{M}+\mathrm{S})$, only surfactant combined with budesonide reduced significantly the edema formation compared to untreated group.

Nevertheless, there are several limitations to direct applicability of our results for clinical practice. First, use of young animals avoids postnatal changes of the lung and hemodynamics which could be observed in neonatal animals. However, due to technical problems with instrumentation of the neonatal animals and due to ethical problems, a part of researchers including our research group (Ohama and Ogawa 1999, Lam et al. 2000, Calkovska et al. 2008) prefer the use of several days to weeks-old animals, especially in the studies where artificial ventilation should be used (as it is in our study). Second limitation of the study is the difference in the dynamics of artificially delivered meconium in animal model vs. spontaneous aspiration of meconium by neonate. And finally, we have to accept some interspecies differences in the immune system between humans and rabbits which may result in some differences in response to induction of the model or to delivered therapy. Considering all the limitations and potential benefits of the study we feel that the results of our study bring new information for research on MAS, for better understanding of the pathophysiology of the syndrome and for evaluation of potentially beneficial treatment approaches. Concluding, budesonide added to exogenous surfactant enhanced the efficacy of surfactant therapy on lung inflammation and oxidation. Administration of the therapy was not accompanied with any obvious adverse effects and we can presume that this combination could be beneficial also in the newborns with MAS.

\section{Conflict of Interest}

There is no conflict of interest.

\section{Acknowledgements}

The authors thank D. Kulišková, Z. Remišová, M. Hutko and M. Petrášková for a technical assistance and our colleagues from Clinics of Neonatology, University Hospital in Martin for collection of neonatal meconium. The study was supported by projects APVV-0435-11, APVV-15-0075, VEGA 1/0291/12, VEGA 1/0305/14 and GUK/80/2016, and the project "Biomedical Center Martin” (ITMS code 26220220187), co-financed from EU sources.

\section{References}

BASU S, KUMAR A, BHATIA BD, SATYA K, SINGH TB: Role of steroids on the clinical course and outcome of meconium aspiration syndrome-a randomized controlled trial. J Trop Pediatr 53: 331-337, 2007.

BHATIA M, MOOCHHALA S: Role of inflammatory mediators in the pathophysiology of acute respiratory distress syndrome. J Pathol 202: 145-156, 2004.

CALKOVSKA A, MOKRA D, DRGOVA A, ZILA I, JAVORKA K: Bronchoalveolar lavage with pulmonary surfactant/dextran mixture improves meconium clearance and lung functions in experimental meconium aspiration syndrome. Eur J Pediatr 167: 851-857, 2008.

CASTELlHEIM A, PHARO A, FUNG M, SAUGSTAD OD, MOLLNES TE: Complement C5a is a key mediator of meconium-induced neutrophil activation. Pediatr Res 57: 242-247, 2005.

CRAIG S, LOPEZ A, HOSKIN D, MARKHAM F: Meconium inhibits phagocytosis and stimulates respiratory burst in alveolar macrophages. Pediatr Res 57: 813-818, 2005.

DA COSTA DE, NAIR AK, PAI MG, AL KHUSAIBY SM: Steroids in full term infants with respiratory failure and pulmonary hypertension due to meconium aspiration syndrome. Eur J Pediatr 160: 150-153, 2001.

DARGAVILLE PA, MILLS JF, HEADLEY BM, CHAN Y, COLEMAN L, LOUGHNAN PM, MORLEY CJ: Therapeutic lung lavage in the piglet model of meconium aspiration syndrome. Am J Respir Crit Care Med 168: 456-463, 2003.

DE BEAUFORT AJ, BAKKER AC, VAN TOL MJ, POORTHUIS BJ, SCHRAMA AJ, BERGER HM: Meconium is a source of pro-inflammatory substances and can induce cytokine production in cultured A549 epithelial cells. Pediatr Res 54: 491-495, 2003. 
FERNANDES AB, ZIN WA, ROCCO PR: Corticosteroids in acute respiratory distress syndrome. Braz J Med Biol Res 38: 147-159, 2005.

GROMMES J, SOEHNLEIN O: Contribution of neutrophils to acute lung injury. Mol Med 17: 293-307, 2011.

KÄÄPÄ P, SOUKKA H: Phospholipase A2 in meconium-induced lung injury. J Perinatol 28 (Suppl 3): S120-S122, 2008.

KATTAN J, GONZÁLEZ A, BECKER P, FAUNES M, ESTAY A, TOSO P, URZÚA S, CASTILLO A, FABRES J: Survival of newborn infants with severe respiratory failure before and after establishing an extracorporeal membrane oxygenation program. Pediatr Crit Care Med 14: 876-883, 2013.

KIRIMI E, TUNCER O, KÖSEM M, CEYLAN E, TAS A, TASAL I, BALAHOROĞLU R, CAKSEN H: The effects of prednisolone and serum malondialdehyde levels in puppies with experimentally induced meconium aspiration syndrome. $J$ Int Med Res 31: 113-122, 2003.

LAM BCC, YEUNG CY, FU KH, WONG KY, CHAN FL, TSOI NS: Surfactant tracheobronchial lavage for the management of a rabbit model of meconium aspiration syndrome. Biol Neonate 78: 129-138, 2000.

LANG JD, MCARDLE PJ, O'REILLY PJ, MATALON S: Oxidant-antioxidant balance in acute lung injury. Chest 122 (6 Suppl): 314S-320S, 2002.

MIKOLKA P, MOKRÁ D, KOPINCOVÁ J, TOMČÍKOVÁ-MIKUŠIAKOVÁ L, ČALKOVSKÁ A: Budesonide added to modified porcine surfactant Curosurf may additionally improve the lung functions in meconium aspiration syndrome. Physiol Res 62 (Suppl 1): S191-S200, 2013.

MIKOLKA P, KOPINCOVA J, MIKUSIAKOVA LT, KOSUTOVA P, CALKOVSKA A, MOKRA D: Antiinflammatory effect of $\mathrm{N}$-acetylcysteine combined with exogenous surfactant in meconium-induced lung injury. Adv Exp Med Biol 934: 63-75, 2016.

MOKRA D, MOKRY J, DRGOVA A, BULIKOVA J, PETRASKOVA M, CALKOVSKA A: Single-dose versus twodose dexamethasone effects on lung inflammation and airway reactivity in meconium-instilled rabbits. J Physiol Pharmacol 58 (Suppl 5): 379-387, 2007.

MOKRA D, TONHAJZEROVA I, MOKRY J, DRGOVA A, PETRASKOVA M, CALKOVSKA A, JAVORKA K: Rapid cardiovascular effects of dexamethasone in rabbits with meconium-induced acute lung injury. Can $J$ Physiol Pharmacol 86: 804-814, 2008.

NEWTON R, LEIGH R, GIEMBYCZ MA: Pharmacological strategies for improving the efficacy and therapeutic ratio of glucocorticoids in inflammatory lung diseases. Pharmacol Ther 125: 286-327, 2010.

NKADI PO, MERRITT TA, PILLERS DA: An overview of pulmonary surfactant in the neonate: genetics, metabolism, and the role of surfactant in health and disease. Mol Genet Metab 97: 95-101, 2009.

OHAMA Y, OGAWA Y: Treatment of meconium aspiration syndrome with surfactant lavage in an experimental rabbit model. Pediatr Pulmonol 28: 18-23, 1999.

SALVESEN B, STENVIK J, ROSSETTI C, SAUGSTAD OD, ESPEVIK T, MOLLNES TE: Meconium-induced release of cytokines is mediated by the TRL4/MD-2 complex in a CD14-dependent manner. Mol Immunol 47: 1226-1234, 2010.

SOUKKA HR, AHOTUPA M, RUUTU M, KÄÄPÄ PO: Meconium stimulates neutrophil oxidative burst. $A m J$ Perinatol 19: 279-284, 2002.

STRANDBERG K, BLIDBERG K, SAHLANDER K, PALMBERG L, LARSSON K: Effect of formoterol and budesonide on chemokine release, chemokine receptor expression and chemotaxis in human neutrophils. Pulm Pharmacol Ther 23: 316-323, 2010.

WANG PW, JENG MJ, WANG LS, FANG LJ, SOONG WJ: Surfactant lavage decreases systemic interleukin-1 beta production in meconium aspiration syndrome. Pediatr Int 52: 432-437, 2010.

WILSON SJ, WALLIN A, DELLA-CIOPPA G, SANDSTRÖM T, HOLGATE ST: Effects of budesonide and formoterol on NF-kappaB, adhesion molecules, and cytokines in asthma. Am J Respir Crit Care Med 164: 1047-1052, 2001. 